\title{
A STUDY ON POISONOUS SNAKEBITES FROM NORTHERN KERALA
}

\author{
K. Prabhakaran ${ }^{1}$, P. K. Mukandan'2, Surag M. K3
}

${ }_{1}^{1}$ Associate Professor, Department of Medicine, Pariyaram Medical College, Pariyaram, Kannur.

${ }^{2}$ Associate Professor, Department of Medicine, Pariyaram Medical College, Pariyaram, Kannur.

${ }^{3}$ Associate Professor, Department of Medicine, Pariyaram Medical College, Pariyaram, Kannur.

ABSTRACT

\section{BACKGROUND}

Poisonous snake bites are an important public health hazard in tropical and subtropical countries, mainly in the rural areas. The types of snake bites have a wide variety depending on the geographical regions.

\section{MATERIALS AND METHODS}

A retrospective observational study on 206 cases of poisonous snake bites, reported from a tertiary care centre in northern Kerala in the year of 2016- January $1^{\text {st }}$ to December $31^{\text {st. }}$

\section{RESULTS}

Majority of the cases were males -126, females accounted for only 80 cases. Most bites reported were of viper, followed by krait, and cobra bites were very rare. The viper bites were the ones seen to develop renal failure as a complication with two cases of mortality. All patients received anti-snake venom within 6 hours of bite. Hypersensitivity reactions were seen with the ASV but were treated with intravenous hydrocortisone and antihistamine without any life-threatening complications.

\section{CONCLUSION}

Early treatment with ASV and recognition of impending complications is vital for better recovery in poisonous snake bites. Premeditation with intravenous hydrocortisone and antihistamine can prevent serious hypersensitivity reaction to ASV and should be routinely practised.

\section{KEYWORDS}

Snake Bite, Anti-snake Venom, Renal Failure, Russell Viper, Common Krait.

HOW TO CITE THIS ARTICLE: Prabhakaran K, Mukandan PK, Surag MK. A study on poisonous snakebites from northern Kerala. J. Evolution Med. Dent. Sci. 2018;7(02):156-158, DOI: 10.14260/jemds/2018/34

\section{BACKGROUND}

Poisonous snake bites are an important public health hazard in tropical and subtropical countries, mainly in the rural areas. Most incidents of poisonous snake bites occur during evening hours and are related to the nocturnal behaviour of most snakes.

Although anti-venoms are being produced by various laboratories in every continent, the burden of snake bite envenomation causing both morbidity and mortality still has a great impact on the population and on health-care systems.(1)

The Venomous Snakes of the World belong to the Families

1. Viperidae - subfamily Viperinae (old world vipers), subfamily Crotalinae (new world and Asian pit vipers);

2. Elapidae (including cobras, kraits, and all Australian venomous snakes), Lamprophiidae (subfamily Atractaspidinae: burrowing asps), and Colubridae (a large family in which most species are nonvenomous and only a few are dangerously toxic to humans).

3. Hydrophidae (all sea snakes, coral snakes).(2)

'Financial or Other Competing Interest': None.

Submission 21-11-2017, Peer Review 23-12-2017,

Acceptance 29-12-2017, Published 08-01-2018.

Corresponding Author:

Dr. K. Prabhakaran,

Associate Professor,

Department of Medicine, Pariyaram Medical College,

Pariyaram, Kannur-670503, Kerala.

E-mail: k.prabhakaran36@yahoo.co.in

DOI: $10.14260 /$ jemds/2018/34
Acute kidney injury (AKI) is one of the most significant complications developing due to snake bite. AKI associated with bites of Russell's viper,(3,4) Saw-scaled Viper,(5) Puff Adder,(6) Pit Viper,(4) Sea snake(7) and Tiger snake.(8) Approximately, $10-15 \%$ of 3000 species of snakes found worldwide are poisonous.(1) In Kerala, around 104 species are known, and of which 37 are poisonous.(1) Snake envenomation is a medical emergency with mortality of up to 10\%.(1) Proper and prompt management often prevents significant morbidity and mortality.

\section{MATERIALS AND METHODS}

A total of 206 patients admitted with a diagnosis of poisonous snake bite were studied with investigations relevant to the clinical presentation of each case and retrospective analysis of the cases were done.

All patients were admitted under Medicine Department of our centre, a tertiary care centre in northern Kerala in the year 2016.

This is a retrospective observational study.

Around $25 \%$ of all cases of snake bites presented to us were non-poisonous and were discharged after the mandatory period of observation, and were managed with supportive measures alone, and only confirmed cases of poisonous snake bites were included in the analysis.

Diagnosis of poisonous snake bite was based upon clinical profile of commonly seen poisonous snakes, described in standard text books, and based on expert opinions. 20-minute whole blood clotting time was used to study coagulopathy in all cases with suspected haematotoxicity. $(9,10)$ Other clinical 
features like evidence of neurological deficits, significant initial local reaction crossing one major joint, or progressive local reaction post-admission were considered indications for anti-snake venom apart from obvious bleeding manifestations and evidences of snake bite related complications.

\section{RESULTS}

A total of 206 cases of poisonous snake bites were reported in our study during the period of one year from January 2016 to December 2016, of which 126 were male and 80 were female. Average age of the victims was 40 , with 15 cases of bites in younger individuals. Most cases presented here in the window period of less than 6 hours after the bite and were treated with Anti-snake venom (Asv). Of all the cases, viper bites accounted for the majority followed by Krait bites, cobra bites were very few as that type of snake is uncommon to this geographical area of the country.

The viper bite cases presented with significant local reaction and coagulopathy. The krait bites had minimal local reaction with features of neurotoxicity in the form of weaknesses as well as haematotoxicity in the form of coagulopathy. The few cobra bites reported had significant local reaction with pure neurotoxicity. Among the cases, viper bites were seen to develop renal failure with two cases of Russell's viper bites, among the complicated viper bites that required haemodialysis succumbing to death.

Epigastric pain as a symptom on presentation was seen with krait bites, which is attributable to the development of submucosal bleeds in the patients.

A few cases of viper bites developed predominantly hepatotoxic features with minimal local reaction and was not found to be responding adequately to anti-snake venom, but did not go on to develop any complications. A retrospective analysis showed that these bites were due to a snake called Malabar pit viper which is indigenous to this region and the antivenin doesn't have any activity against this type of snake bites.

Anaphylactic reactions to the anti-snake venom were also noticed and they were treated with intravenous hydrocortisone and antihistamine, with few cases requiring adrenaline injections. Most cases premedicated with hydrocortisone and antihistamines did not develop any significant hypersensitivity reactions.

20-minute whole blood clotting time was taken for monitoring and detecting coagulopathy and was found to be very reliable in correlation with the degree of envenomation.

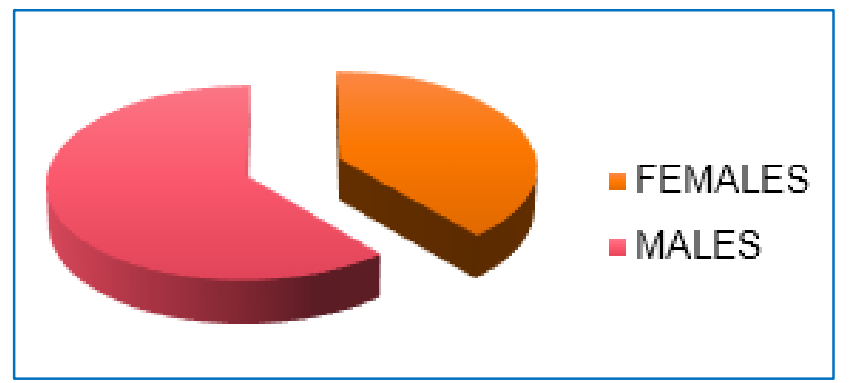

Figure 1. Gender wise Distribution of Cases

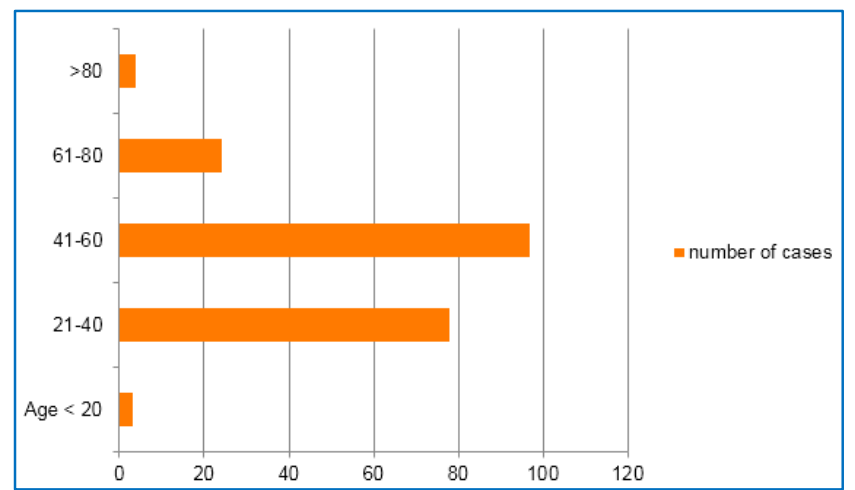

Figure 2. Age wise Distribution of Cases

\section{DISCUSSION}

Poisonous snake bite is a common cause of morbidity and mortality among rural populations in our country. In this part of the state of Kerala, we have encountered various types of snake bites of which Russell's viper bites predominate the cases, followed by common krait and cobra bites having least incidents. Malabar pit viper bites not seen in other areas of the country were also encountered in this study. Haematotoxicity in the form of coagulopathy and local reaction in the form of swelling, oedema, ulceration were mostly seen in the cases.

All the cases received ASV within the window period of 6 hours and some cases of Russell's viper bites developed renal failure with two cases of mortality. All other cases did not develop any complications and were completely cured with ASV and supportive medications.

Hypersensitivity reactions to lyophilised ASV were seen among some of the cases and all of them recovered with intravenous hydrocortisone and antihistamine, with premedication proving to be helpful in reducing albeit preventing any hypersensitivity reactions.

Morbidity associated with poisonous snake bites and their complications were seen to be more in elderly individuals than younger ones.

\section{CONCLUSION}

Snake bites are important causes of morbidity in this part of the country and early treatment with Anti-snake venom and recognition of impending complications is a determinant for better recovery. Premeditation with intravenous hydrocortisone and antihistamine can prevent serious hypersensitivity reaction and should be routinely done. In general, snake bites lead to mortality from renal failure and so renal replacement therapies if initiated early could be lifesaving.

\section{REFERENCES}

[1] Simpson ID, Norris RL. The global snakebite crisis-a public health issue misunderstood, not neglected. Wilderness Environ Med 2009;20(1):43-56.

[2] Chippaux JP. Snake-bites: appraisal of the global situation. Bull World Health Organ 1998;76(5):515-24.

[3] Gutie'rrez JM, Theakston RD, Warrell DA. Confronting the neglected problem of snake bite envenoming: the need for a global partnership. PLoS Med 2006;3(6): e150. 
[4] Kasturiratne A, Wickremasinghe AR, de Silva N, et al. The global burden of snakebite: a literature analysis and modelling based on regional estimates of envenoming and deaths. PLoS Med 2008;5(11):e218.

[5] Ali Z. Snake bite: a medical and public health problem in Pakistan. In: Gopalakrishnakone P, Chou LM. eds. Snakes of medical importance (Asia Pacific region). Singapore National University Singapore 1990:447-61.

[6] WHO. Zoonotic disease control: baseline epidemiological study on snakebite treatment and management. Wkly Epidemiol Rec 1987;42:319-20.
[7] Kularatne SA. Epidemiology and clinical picture of the Russell's viper (Daboia russelii russelii) bite in Anuradhapura, Sri Lanka: a prospective study of 336 patients. Southeast Asian J Trop Med Public Health 2003;34(4):855-62.

[8] Sarker M, Sarker N, Patwary S. Epidemiological survey of snakebite incidences in Bangladesh. J Biol Sci 1999;8:53-68.

[9] de Silva A. Snake bite in Anuradhapura District. The Snake 1981;13(2):117-30.

[10] Sawai Y. Study on deaths due to snakebite in Anuradhapura District, Sri Lanka. The Snake 1984;16:7-15. 